opacities have been described (Anton, 1967 ; Leathart, 1967), but it seems evident that a large proportion of pleural abnormalities remain undiscovered and that prevalence rates based on radiographic surveys are considerably underestimated.

Pulmonary fibrosis occurred in a variety of trades in which exposure was intermittent, and appeared to be a definite risk in some cases of extensive pleural thickening. In 50 such cases seen locally during the last five years an attempt was made to apply the distinction drawn by Elmes (1966) between circumscribed hyaline fibrosis in the parietal pleura and a diffuse pleural thickening with ill-defined margins, most pronounced over the lower lobes, which he relates to underlying parenchymal disease. There was considerable overlap between the two varieties in some of our cases, but it would be reasonable to regard 26 as parietal pleural thickening and 24 as mainly diffuse lower-zone fibrosis. All five cases in which a diagnosis of pulmonary fibrosis was subsequently established occurred among the 24 with diffuse lower-zone fibrosis.

A possible explanation for the predominance of pleural over parenchymal changes is that the intermittent exposure experienced in most of these cases has allowed sufficient time to elapse for the appearance of pleural reactions, while the dust concentrations were insufficient to give rise to pulmonary fibrosis as the presenting feature.

A further cause of anxiety is the possibility of a relation between pleural fibrosis and malignancy. Our first case of mesothelioma was preceded by extensive parietal pleural thickening for more than five years. Others have developed in the neighbourhood of previously identified limited pleural plaques. In addition to those with recognized pleural fibrosis there are at present in the dockyard over 1,200 men whose first occupational exposure to asbestos was more than 30 years ago, and a further 1,000 who have been environmentally exposed for a similar period. The large number of retired men living in the district must be added to these in order to gain an impression of the number who may be at risk.

It is hoped that the long-term study of a series of all types of pleural thickening will help to assess the added risks of malignancy and morbidity from extending fibrosis.

We would like to thank Surgeon-Commander P. G. Harries, Royal Navy, for his close collaboration and for help with pulmonary function studies ; Dr. J. C. Gilson for encouragement and valued advice; the Admiral Superintendent of the Dockyard and his staff for their co-operation; and the staff of the Mass Radiography Service for their skilled work. The investigation was supported by a research grant from the South-western Regional Hospital Board.

\section{REFERENCES}

Anton, H. C. (1967). Brit. f. Radiol., 40, 685.

Elmes, P. C. (1966). Postgrad. med. 3 ., 42, 623.

Harries, P. G. (1968). Ann. occup. Hyg., 11, 135.

Hourihane, D. O'B. Lessof, L., and Richardson, P. C. (1966). Brit. med. F., 1, 1069.

Kiviluoto, R. (1960). Acta Radiol. (Stockh.), Suppl. No. 194.

Leathart, G. L. (1967). Unpublished.

Selikoff, I. J. (1965). Ann. N.Y. Acad. Sci., 132, 351.

\title{
Chloroquine: Ophthalmological Safety, and Clinical Assessment in Rheumatoid Arthritis
}

\author{
S. P.'B. PERCIVAL,* M.A., M.B., D.o. ; I. MEANOCK, $†$ M.D., M.R.C.P.
}

Brit. med. F., 1968, 3, 579-584

\begin{abstract}
Cummary : 272 patients on long-term chloroquine therapy were assessed with respect to ocular toxicity and clinical benefit. A simple scheme for rendering patients ophthalmologically safe is presented, employing the recording of central fields to red targets. Under this it was possible to diagnose a state of premaculopathy, which was reversible on stopping treatment. The incidence of premaculopathy was $41 \%$ in 143 patients who otherwise displayed no abnormality of the fundus oculi and who had received a mean total dose of $410 \mathrm{~g}$. of chloroquine phosphate or the hydroxychloroquine sulphate equivalent. Under this joint ophthalmological and rheumatological supervision it was considered that the minor side-effects that may be caused by chloroquine are outweighed by its therapeutic value.
\end{abstract}

\section{Introduction}

In spite of undoubted therapeutic value in centain disorders, the use of the antimalarials chloroquine phosphate (Avlochlor), hydroxychloroquine sulphate (Plaquenil), and chloroquine sulphate (Nivaquine) has been losing favour in clinical practice

\footnotetext{
* Ophthalmic Registrar, Royol Berkshire Hospital, Reading. Present address: The Eye, Ear, ond Throat Hospital, Shrewsbury.

+ Consultant Physician in charge of Rheumatic Diseases and Physical Medicine Departments, Reading and District Hospitals Group.
}

because of ocular toxicity. It is the purpose of this paper to show how antimalarials may be rendered ophthalmologically safe and to assess the clinical and functional status of a group of patients on continuous antimalarial therapy, the majority of whom had rheumatoid disease.

\section{Material and Methods}

The 272 outpatients taking part in the survey were referred from the departments of rheumatology and dermatology to the ophthalmic outpatient department during 1964 and the early part of 1965 . Their age and sex are shown in Table $I$.

TABLB I.-Age and Sex

\begin{tabular}{c|c|c|c|c|c|c|c|c}
\hline \multirow{3}{*}{ Patients } & \multicolumn{3}{|c|}{ Male Aged } & \multicolumn{3}{|c|}{ Female Aged } & \multirow{2}{*}{ Total } \\
& $20-40$ & $41-60$ & $61-80$ & $20-40$ & $41-60$ & $61-85$ & \\
\hline \begin{tabular}{l|c|c|c|c|c|c} 
Rheumatoid \\
Skin
\end{tabular} & 8 & 36 & 25 & 28 & 118 & 37 & 253 \\
\hline
\end{tabular}

The standard daily dose of antimalarial was $250 \mathrm{mg}$. of chloroquine phosphate or $200 \mathrm{mg}$. of hydroxychloroquine sulphate. Five patients had also received courses of chloroquine sulphate. Ninetythree received double the daily dose during the first part of their course, and 43 received half the daily dose during the course when control at this level seemed satisfactory. 


\section{Ocular Examination}

Ocular examination took place where possible before therapy was begun; it was repeated after approximately 10 months and then at four-monthly intervals. It comprised:

(1) The recording of visual acuity.

(2) The assessment of colour vision by means of the Ishihara pseudoisochromatic plates.

(3) The recording of central fields on the tangent screen to a $1-\mathrm{mm}$. white and a 7.5- $\mathrm{mm}$. red target at 1 metre distance. A central field defect to red was said to be present if there was either a relative or an absolute scotoma to red colour between $4^{\circ}$ and $9^{\circ}$ from fixation. At 1 metre distance a 7.5- $\mathrm{mm}$. target may be considered fairly large, so that the red colour may be seen clearly to $15^{\circ}$ from fixation, though occasionally it may become lost outside $10^{\circ}$ from fixation. When a relative scotoma was present this colour was described as becoming pink or orange, and when absolute the colour was not recognized. In most cases the colour returned to the original red hue outside the scotoma. Central fields to red targets were assessed in 230 patients and in 100 control subjects. The latter were selected at random and were matched for age and sex; all had healthy maculae and gave normal readings to the Ishihara plates. Perimetry and Amsler charting were performed in all retinopathy patients.

(4) Examination of the fundus under mydriasis with particular attention to the foveal reflex.

(5) Slit-lamp examination of the corneae for the presence of keratopathy.

(6) Serial photography was performed at intervals of 6 to 18 months in 95 patients.

\section{Rheumatoid Evaluation}

The 253 patients with rheumatoid arthritis satisfied the American Rheumatism Association criteria for classical or definite peripheral rheumateid arthritis. All were over 20 years of age at onset of disease, and the disease had been present for more than one year at onset of trial. Therapies which excluded patients were systemic corticosteroids and gold therapy if within one year before admission to the trial. The patients were assessed according to the following five indices:

(1) Functional status: grade v, able to carry out all usual activities without handicap ; grade iv, able to carry out all usual activities despite handicap of discomfort or limited movement; grade iii, forced to change work and leisure habits by reason of disability; grade ii, largely incapacitated, able to carry out few of usual activities or self care; grade $i$, wholly incapacitated.

(2) Number of clinically active joints, determined by any two of three findings: (a) tenderness on pressure, (b) pain on passive movement, and (c) swelling.

(3) Erythrocyte sedimentation rate, Westergren method-one-hour reading.

(4) Haemoglobin estimation.

(5) Patient's own assessment of fitness-the same, worse, improved.

\section{Dermatological Assessment}

Patients were assessed by subjective and objective examination of the size and severity of skin lesions at intervals of four to six months.

\section{Results and Comments}

\section{Examination of Macula}

A diagnosis of chloroquine maculopathy was made in 11 of the 272 patients when the characteristic ring or bullseye lesion was visualized. By careful serial examination early maculopathy was diagnosed in a further five patients because of pigment irregularity and loss of the foveal reflex in maculae previously quite normal. These are at present the earliest known signs of macula toxicity (Henkind, Carr, and Siegel, 1964 ; Nozik, Weinstock, and Vignos, 1964). On consideration of the different preparations of drug it was found that maculopathy had developed in 13 out of the 141 patients who had taken over $225 \mathrm{~g}$. of chloroquine phosphate, in two out of the four who had taken over $180 \mathrm{~g}$. of chloroquine sulphate, and in 1 out of 48 who had taken over $180 \mathrm{~g}$. of hydroxychloroquine sulphate.

In 101 patients the foveal reflex seemed to be absent, and in 65 of these the macula appeared to be granular, but it was impossible to tell whether there had been any toxic change except in the 21 (see later) in whom a gradual disappearance of the foveal reflex had been noted. Fine macular pigment mottling and loss of the foveal reflex are well-known age changes in the normal eye (Braley, 1966). Fig. 1 shows this foveal change with age.

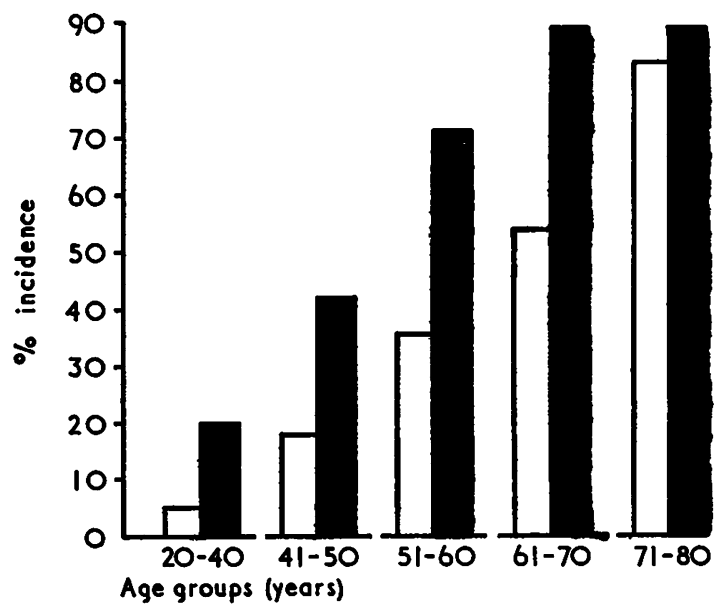

FIG. 1.-Disappearance of the foveal reflex with age. White columns give the incidence of absent foveal reflex in different age groups of 138 patients with normal maculae and no red field defects. Black columns give the incidence in 59 patients on chloroquine with red field defects which disappeared on discontinuation of treatment.

\section{Field Testing}

Paracentral ring scotomata to white targets were found in only seven patients out of the 16 with maculopathy (Table II). All were advanced cases and the defect corresponded with the parafoveal bullseye lesion in each. In all but one the defects were irreversible. Amsler defects were found in oniy six of the patients, again with advanced maculopathy ; so that, in agreement with Adlakha, Crews, Shearer, and Tonks (1967), it is felt that these tests are of no value in the detection of early toxicity.

TABLE II.-Central Field Assessment in 372 Subjects

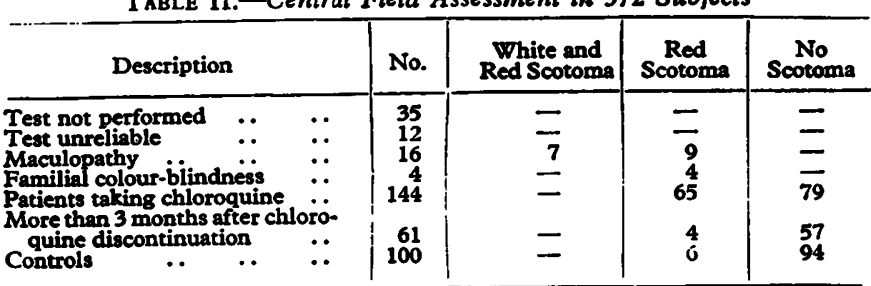

The peripheral fields were found to be within normal limits in all patients except for a few with pathology unrelated to chloroquine administration, and in no patient was there ophthalmoscopic evidence for pigmentary change in the peripheral retina.

Two hundred and thirty patients had their central fields assessed by use of red targets (Table II): 12 were excluded because the patient was unreliable or because changes in the fundus precluded a normal result; four others were excluded 
because of established familial colour-blindness. Nine of the patients had early maculopathy without paracentral scotomata to white targets; these all had absent foveal reflexes and paracentral scotomata to red, and in six the red field returned to normal within 18 months after cessation of therapy.
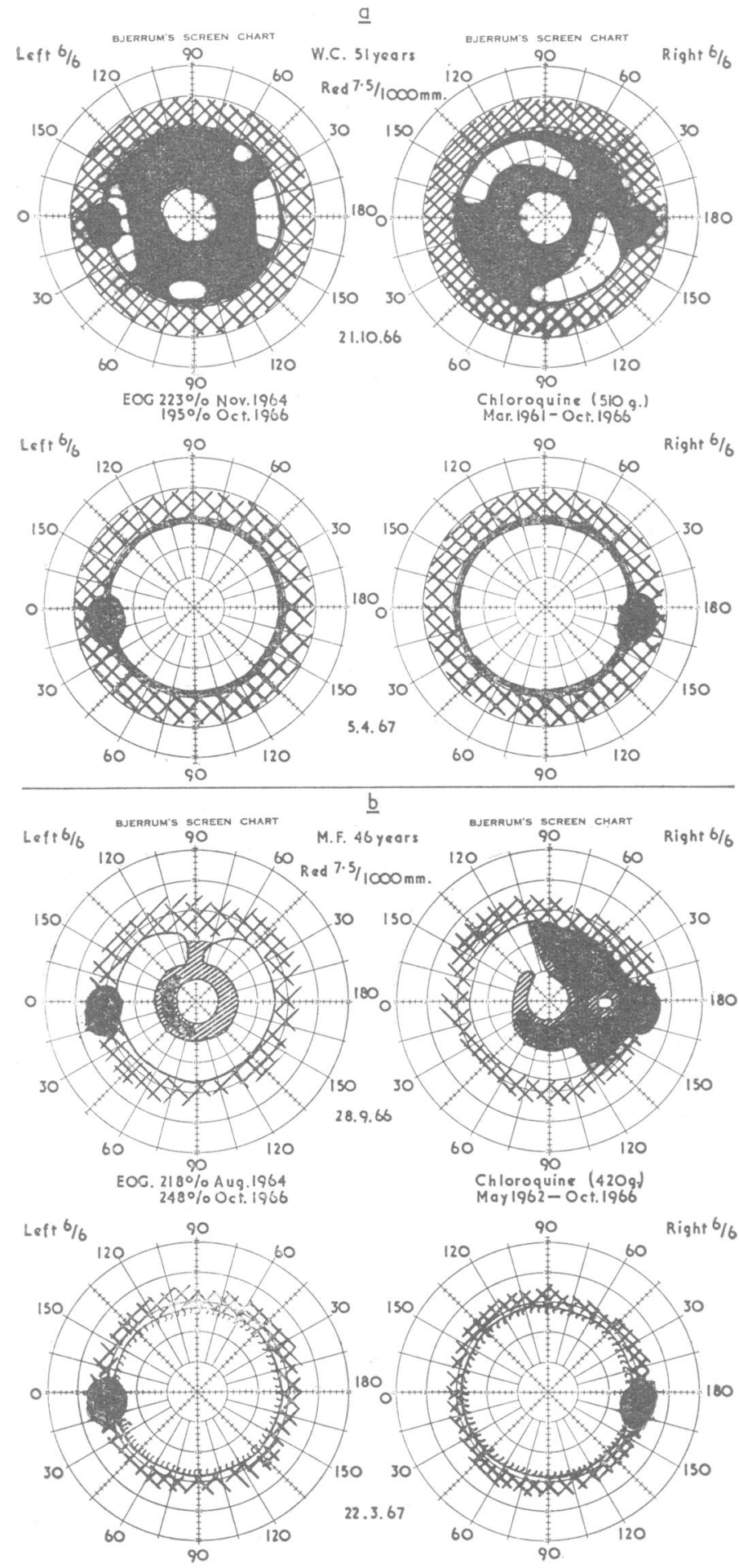

Fig. 2.-Examples of chloroquine premaculopathy. Top-A man aged 51 who had received a to:al dose of $510 \mathrm{~g}$. of chloroquine phosphate over five and a half years. Large paracentral absolute scotoma to a 7.5/1,000 five and a half years. Large paracentral absolute scotoma to a $7.5 / 1,000$ $\mathrm{mm}$. red target were found. These had disappeared within six months of
discontinuation; fields were always full to $1 / 1,000 \mathrm{~mm}$. white targets. Uncorrected visual acuity $6 / 6$ each eye. Foveal reflexes present throughout trial. Bottom-A woman aged 46 who had received a total dose of $420 \mathrm{~g}$. of chloroquine phosphate over four years five months. Paracentral scoiomata were found to a $7.5 / 1,000 \mathrm{~mm}$. red target which were partly relative (shaded area) and partly absolute. These had disappeared pithin six months of discontinuation; fields were always full to $1 / 1,000$ $\mathrm{mm}$. white targets. Uncorrected visual acuity $6 / 6$ each eye. Foveal
One hundred and forty-four of the patients had maculae within normal limits and were concurrently on chloroquine therapy: 79 had normal red central fields and 65 had relative or absolute paracentral red scotomata (Fig. 2). There was little relation to total dose (Table III). In a proportion of each group the foveal reflex was absent, but change in this reflex occurred in none of the former group and in 21 of the latter. Thus the red field defect correlates well with the loss of the foveal reflex, but appears to be a much earlier feature in the development of maculopathy. Indeed, the foveal reflex remained present in 11 out of the 17 patients with reversible red field defects under the age of 50 (see also Fig. 1).

TABLE III.-Comparison of Incidence of Central Field Scotoma to Red Targets in Chloroquine Patients and Healthy Controls

\begin{tabular}{|c|c|c|c|c|c|c|}
\hline \multirow{2}{*}{\multicolumn{2}{|c|}{ Patients }} & \multirow{2}{*}{$\begin{array}{l}\text { No. } \\
\text { Assessed* }\end{array}$} & \multirow{2}{*}{$\begin{array}{c}\text { Mean } \\
\text { Total } \\
\text { Dose } \\
\text { (g.) }\end{array}$} & \multicolumn{2}{|c|}{ Red Scotomata Present } & \multirow{2}{*}{$\begin{array}{l}\text { Incidence } \\
\% \text { of } \\
\text { Irrevers- } \\
\text { ibility }\end{array}$} \\
\hline & & & & $\begin{array}{c}\text { Rever- } \\
\text { sible }\end{array}$ & $\begin{array}{c}\text { Irrever- } \\
\text { ible }\end{array}$ & \\
\hline $\begin{array}{l}\text { Chloroquine total: } \\
100-250 \mathrm{~g} . \\
250-500 \mathrm{~g} . \\
\text { Over } 500 \mathrm{~g} \text {. } \\
\text { Controls } \quad .\end{array}$ & $\begin{array}{l}\cdots \\
\cdots \\
\cdots\end{array}$ & $\begin{array}{l}37 \\
68+ \\
39 \\
100\end{array}$ & $\begin{array}{l}188 \\
368 \\
694\end{array}$ & $\begin{array}{l}16 \\
25 \\
13\end{array}$ & $\begin{array}{l}1 \\
2 \\
2 \\
6\end{array}$ & $\begin{array}{l}2.7 \\
3.5 \\
5.1 \\
0.5\end{array}$ \\
\hline
\end{tabular}

* All those with familial colour defects or abnormal maculae were excluded.

i Including one patient not followed up on discontinuation.

It is proposed, therefore, to use the term "premaculopathy" for those maculae that appear to be within normal limits yet either develop paracentral red scotomata or lose the foveal reflex during therapy. The lowest dose under which premaculopathy developed was $120 \mathrm{~g}$. of chloroquine phosphate administered over 15 months.

Of the 65 patients thought to have premaculopathy on account of paracentral red scotomata 64 were followed up after discontinuation of therapy: the fields returned to normal within a year in 59. The incidence of irreversible red scotomata was therefore 5 out of $143(3.5 \%)$.

The remaining 61 patients had been off chloroquine for more than three months (and a mean period of 18 months) when their red fields were assessed. They had received a mean total dose of $297 \mathrm{~g}$. of chloroquine phosphate (or the hydroxychloroquine sulphate equivalent). There were only four with scotomata to red. This is further evidence of the reversibility of the premaculopathy defect.

Of the 100 matched control subjects six had relative paracentral red scotomata. These defects were presumed to be physiological and possibly due to a slight variation of cone configuration near the macula. The incidence of red scotomata in patients on chloroquine that were found to be irreversible after discontinuation was only $3.5 \%$ compared with $6 \%$ in the control subjects (Table III) ; so it is reasonable to suppose that these were also physiological, and, therefore, that the true chloroquine red scotomata were all reversible.

\section{Colour-blindness}

Of 239 patients tested with the Ishihara plates for red/green colour defects 227 showed normal results, including six with early maculopathy. The 12 with abnormal readings all had red field defects; they included five with maculopathy and four with familial colour blindness. Three patients faltered on reading the plates, but their defects were mild and could have been associated with premaculopathy or have been familial.

The Farnsworth D 15 panel has been shown to give normal results in cases of retinopathy (Okun, Gouras, Bernstein, and Von Sallman, 1963 ; Nozik et al., 1964); and, though Okun et al. (1963) considered the Hardy-Rand-Rittler pseudoisochromatic plates to be useful, Henkind et al. (1964) described 12 cases of retinopathy with no abnormalities to this test. 
These tests are therefore of no value in screening chloroquine retinopathy. However, the Ishihara test may be used in the early stages of chloroquine treatment in order to eliminate familial defects which would give rise to false-positive results on red field testing.

\section{Serial Photography}

Fundus photography was performed in 139 patients and serially in 95 . The serial photographs were screened simultaneously and assessed by an independent observer. In 41 patients premaculopathy had been diagnosed at the time of the second or subsequent photograph, but in no case could any change at the macula be discerned from the appearance of the first photograph. Of 12 patients photographed in whom maculopathy had been diagnosed obvious lesions were present in six (Fig. 3), but photographically the other six appeared quite normal.

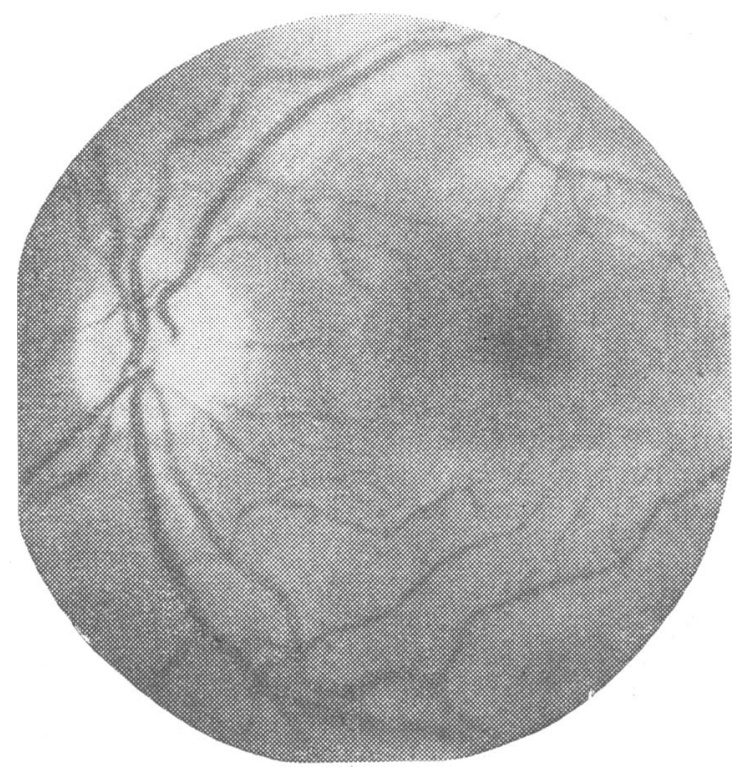

Fig. 3.-Chloroquine maculopathy.

\section{Arteriolar Narrowing}

Chloroquine phosphate and hydroxychloroquine sulphate are said to cause narrowing of the retinal vessels (Hobbs, Sorsby, and Freedman, 1959; Nozik et al., 1964). In this series the vessels were considered to be narrowed in only 31 of 272 patients ; 19 of these had been photographed and the narrowing confirmed independently in all but three. Of the 31 patients 17 had normal maculae, 9 had premaculopathy, and 5 had maculopathy ; but in these three groups the incidence of senile or hypertensive changes contributing to the narrowing was $77 \%, 55 \%$, and $20 \%$ respectively. It is therefore considered that arteriolar narrowing exists particularly in advanced cases of retinopathy, but is only of minor importance. There were no cases of optic atrophy.

\section{Keratopathy}

The slit-lamp appearance of the corneal deposits has been described in detail by Hobbs, Eadie, and Somerville (1961). In the 272 patients under consideration the shortest period before development of keratopathy was three months. The incidence was $71 \%$ of those who had had a total dose of over $500 \mathrm{~g}$. of chloroquine phosphate or the hydroxychloroquine sulphate equivalent, $64 \%$ of those who had had between 250 and $500 \mathrm{~g}$., and $35 \%$ of those who had had less than $250 \mathrm{~g}$.

Seventy-six patients with keratopathy were re-examined after cessation of therapy: the deposits had disappeared in all, though in 26 there remained a linear mark of varying intensity resembling a Hudson-Stähli line. Keratopathy was never considered a reason for termination of therapy except in two patients in whom it was causing symptoms of haloes and blurred vision.

\section{Visual Acuity}

Of the 272 patients 35 had an acuity of less than $6 / 6$ in one or both eyes; five instances were attributed to overt maculopathy, but these were all patients who had never received ophthalmological supervision. In addition, there were two whose acuity became reduced from $6 / 5$ to $6 / 6$ as the result of early maculopathy.

There were no cases of delayed retinopathy and no cases where the acuity continued to deteriorate after therapy had been stopped, though in two patients with maculopathy the visual symptoms appeared to progress for several months. Progression of maculopathy after discontinuation of treatment has been noticed by Penner and Somers (1962) and by Okun et al. (1963). It is suggested that the occurrence of "delayed retinopathy" is very unlikely. It may be that the two cases described by Burns (1966) who had not undergone ocular examination at the time of discontinuation were examples of progressive but not delayed retinopathy.

\section{Visual Symptoms}

Sixty-two patients in the series complained ot ocular symptoms, which in 46 could be related to chloroquine. Thus 32 patients noticed a blur when reading, often soon after the beginning of therapy and when receiving double the standard dose. This has been noticed by other authors, including Conan (1949) and Patel (1953). It is thought to be due to a transient increase in presbyopia. In nine patients complaints of blurring or distortion of images were attributed to maculopathy ; two complained of haloes due to keratopathy; and there were three instances of diplopia, which in each case disappeared every time the drug was discontinued: the first was due to an isolated superior oblique palsy, the second a latent convergent squint which became manifest during therapy, and the third an exacerbation of superior rectus weakness.

\section{Non-ocular Toxicity}

Minor side-effects occurred in 31 patients: 16 complained of gastrointestinal disturbance and five of giddiness, but in nine of these the disturbance occurred only with double the standard dose. Nine patients complained of a rash ; two-thirds of these were light-sensitive. In five patients, usually already of a fair complexion, the hair became bleached. No case of neuromyopathy or psychosis was recorded.

\section{Seven-year Follow-up}

Seventy-six patients had started therapy during 1960 or before at a time when there were no regular eye follow-ups. Thirteen of these developed maculopathy. Fifty-four of the others underwent examination seven years later. All were found to have normal maculae ophthalmoscopically, though some of those still taking the drug had developed the reversible premaculopathy. There was no evidence of delayed toxicity. 


\section{Assessment of Therapeutic Effects}

Recording of the clinical state of patients at entry to the trial according to the indices used is shown in Table IV.

\begin{tabular}{|c|c|c|c|c|c|c|c|}
\hline \multicolumn{8}{|c|}{ Functional Status } \\
\hline $\mathbf{v}$ & & iv & 1 & iii & ii & & $\mathrm{i}$ \\
\hline 47 & & 134 & 1 & 64 & 8 & & 0 \\
\hline \multicolumn{8}{|c|}{ Number of Clinically Active Joints } \\
\hline$<5$ & & $5-9$ & 1 & $10-15$ & $>15$ & & \\
\hline 0 & & 107 & & 112 & 34 & & \\
\hline \multicolumn{8}{|c|}{ Erythrocyte Sedimentation Rate (mm./hour) } \\
\hline$<15$ & 1 & $15-29$ & & $30-49$ & $50-70$ & & $>70$ \\
\hline 31 & 1 & 43 & & 109 & 34 & & 36 \\
\hline \multicolumn{8}{|c|}{ Haemoglobin (\%) } \\
\hline$>74$ & I & $74-65$ & 1 & 64-55 & $<55$ & & \\
\hline 117 & ! & 86 & 1 & 43 & 7 & & \\
\hline
\end{tabular}

At the conclusion of the trial the functional status had been improved in 153 patients and the number in grade iv had increased from 134 to 165 ; the E.S.R. fell to a lower grade in 160 patients ; the haemoglobin rose by more than $10 \%$ in 207 patients; but in only 43 patients was the number of clinically active joints reduced by more than five. Subjective improvement was claimed by 129 patients, but this may have been aided by continuous analgesics.

Objective rheumatoid improvement was considered to have occurred if three or more of the four indices changed for the better. All patients were then grouped into four categories as follows: (1) subjective and objective benefit (improvement in three or more indices); (2) objectively unchanged or deterioration halted and improvement in one or two indices; (3) objective deterioration; and (4) withdrawn from trial because of failure in administration, failure in attendance, minor sideeffects, or the simultaneous use of anti-inflammatory agents.

These categories are summarized in Table V. Under category (2) there were 54 who also presented a clinical relapse within three months of discontinuing chloroquine. It was considered that chloroquine was of clinical value in 181 out of 220 rheumatoid patients $(82 \%)$. Improvement was unequivocal in $83(38 \%)$. The drug was of benefit in $100 \%$ of patients with discoid lupus erythematosus.

TABLE V.-Therapeutic Effect of Chloroquine

\begin{tabular}{|c|c|c|c|c|}
\hline \multirow{2}{*}{ Disorder } & \multicolumn{4}{|c|}{ Category } \\
\hline & 1 & 2 & 3 & 4 \\
\hline 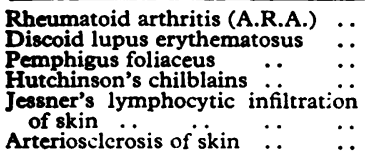 & $\begin{array}{r}83 \\
14 \\
1 \\
1\end{array}$ & 98 & 39 & 33 \\
\hline
\end{tabular}

\section{Discussion}

From the above results the two most important tests for ocular toxicity are the charting of the central field to a red target and the ophthalmoscopic examination of the fovea. Both are simple and quick, but must be performed serially. As the effects of retinopathy when once apparent may be irreversible and even progressive, the state of premaculopathy has been introduced, the effects of which are considered to be always reversible.

For the diagnosis of premaculopathy, although there is good correlation between the red central field defect and loss of the foveal reflex, the changes in the red field are the more reliable.
The testing of retinal thresholds to red light in dark-adapted subjects has also been shown to demonstrate early effects of chloroquine toxicity (Carr, Gouras, and Gunkel, 1966 ; Gunkel, $1967)$; it is possible that fundus fluorescein photography will prove of value (Adlakha et al., 1967). However, these tests are not available at every ophthalmic outpatient department. Electroretinography and dark-adaptation-time studies have been shown to be unreliable (Okun et al., 1964 ; Carr et al., 1966). If a patient has physiological red field defects at the beginning of therapy, or is unreliable for field testing, or is colour-blind, extreme caution is necessary, but serial electro-oculographic recordings and binocular examination of the macula with a slit-lamp and contact lens may be useful (Percival, 1967).

The value of antimalarials in discoid lupus and other skin disorders is undoubted (Kennedy, O'Quinn, Henington, and Perret, 1963 ; Rees and Maibach, 1963), and there have been several reports of benefit in rheumatoid arthritis (Freedman and Steinberg, 1960 ; Popert, Meijers, Sharp, and Bier, 1961 ; Scull, 1962), particularly when gold or steroids are contraindicated (Kersley, 1966). The results of our series confirm this therapeutic benefit.

\section{Conclusions}

Ophthalmologists concerned with supervision of chloroquine patients should make initial examinations before therapy is begun, repeat these examinations after a year (if doses used are similar to those standard in this paper), and thence at fourmonthly intervals. Each examination should include the recording of central fields to a red target as already outlined, and examination of the macula and foveal reflex under mydriasis. If the central field is at any time abnormal the physician concerned should be strongly advised against the continuation of therapy unless the patient be referred to a centre for specialized investigations.

It is possible to diagnose a state of premaculopathy which is reversible after stopping treatment. The incidence of premaculopathy was found to be $41 \%$ of 143 patients who otherwise displayed no abnormality of the fundus oculi.

The foveal reflex tends to become lost and the macula pigment irregular with advancing age, but loss of the foveal reflex is a useful guide in diagnosis of premaculopathy if the patient has normal and youthful maculae before therapy is begun.

Testing of colour vision, Amsler charting, perimetry, central field charting to white objects, and serial photography are considered to be of no value in screening patients for ocular toxicity.

Progressive retinopathy may occur in advanced cases of toxicity after discontinuation of therapy, but there is no evidence to substantiate the possibility of delayed retinopathy.

The most common cause of visual symptoms is a transient increase in presbyopia, which may occur soon after therapy is begun, especially if high doses are used.

Keratopathy may be expected in more than half of patients, but it is always reversible.

Clinical benefit from long-term chloroquine treatment in moderate doses was obtained in $82 \%$ of rheumatoid patients and $100 \%$ of patients with discoid lupus erythematosus.

We are grateful to Mr. E, W. Dorrell for his thoughtful advice and for the use of his clinics, during which the major part of the work for this paper was carried out, to Dr. H. T. Calvert for referra] of skin patients, and to Dr. J. McMillan for his help in the independent assessment of photographs.

\section{REFERENCES}

Adlakha, D., Crews, S. J., Shearer, A. C. I., and Tonks, Eva L. (1967), Trans. Ophthal. Soc. U.K., 87, 267.

Braley, A. E. (1966). Amer. F. Ophithal.; 61, 1.

Burns, R. P. (1966). New Engl. F. Med., 275, 693.

Carr, R. E., Gouras, P., and Gunkel, R. D. (1966). Arch. Ophthal., 75, 171 . 
Conan, N. J. (1949). Amer. F. Med., 6, 309.

Gunkel, R. D. (1967). Arch. Ophthal., 77, 22

Henkind, P., Carr, R. E., and Siegel, I. M. (1964). Arch. Ophthal., 71, 157.

Hobbs, H. E., Eadie, S. P., and Somerville, F. (1961). Brit. F. Ophthal., 45. 284.

Hobbs, H. B., Sorsby, A., and Freedman, A. (1959). Lancet, 2, 478. Kennedy, C. B., O'Quinn, S. E., Henington, V. M., and Perret, W. J. (1963). Sth. med. \%. (Bgham, Ala.), 56, 760 .

Kersley, G. D. (1966). 'Practitioner, 197, 57.
Nozik, R. A., Weinstock, F. J., and Vignos, P. J. (1964). Amer. \%. Ophthal., 58, 774 .

Okun, E., Gouras, P., Bernstein, H., and Von Sallmann, L. (1963). Arch. Ophthal. $69,59$.

Patel, J. C. (1953). Brit. med. 7., 1, 811.

Penner, R., and Somers, K. (1962). Amer. f. Ophthal., 54, 381.

Percival, S. P. B. (1967): Trans. Ophthal. Soc. U.K., 87, 355.

Popert, A. J., Meijers, K. A. E., Sharp, J., and Bier, F. (1961). Ann. rheum. Dis., 20, 18.

Rees, R. B., and Maibach, H. I. (1963). Arch. Derm., 88, 280.

Scull, E. (1962). Arthr. and Rheum., 5, 30.

\title{
Nephrotic Syndrome with Heart Disease : A Reappraisal
}

\author{
P. J. HILTON,* M.A., M.B., M.R.C.P.; N. F. JONES,* M.A., M.D., M.R.C.P. \\ J. R. TIGHE,* M.D., B.SC., M.R.C.P., M.C.PATH.
}

[With Special Plate facing Page 575]

Brit. med. F., 1968, 3, 584-586

\begin{abstract}
Summary: The evidence that heart failure alone may cause a nephrotic syndrome is inconclusive. Mercurial diuretics, which have also been implicated as a cause of the nephrotic syndrome, had been given in 23 of the 24 well-documented cases.

Two cases of heart disease and nephrotic syndrome are described. Glomerular lesions were minimal on light microscopy, but thickening of the glomerular tuft basement membrane and partial fusion of the epithelial cell foot processes were apparent on elecronmicroscopy. The response to prednisone was such as to justify a trial of corticosteroid therapy in such cases despite the presence of cardiac disease.
\end{abstract}

\section{Introduction}

Standard textbooks of renal disease usually include heart failure as one cause of the nephrotic syndrome (Strauss and Welt, 1963 ; Robson, 1967). However, review of the literature shows that patients who have developed this complication have invariably been receiving mercurial diuretics which are themselves alleged to cause the nephrotic syndrome.

The purposes of this paper are threefold: to describe two patients with heart disease who developed the nephrotic syndrome, one of whom had never received mercurial diuretics; to describe the light and electronmicroscopic appearances of the renal biopsies of these patients; and to review the evidence for the statement that heart failure may cause the nephrotic syndrome.

\section{Case 1}

A woman aged 61 was diagnosed in 1957 as having mitral stenosis and incompetence. She remained relatively symptom-free until December 1966, when she complained of increasing dyspnoea and ankle oedema. Cardiac failure was diagnosed, and treated with digoxin, a thiazide diuretic, and weekly injections of mersalyl. There was a good response and the patient remained well until September 1967, when increasing oedema rapidly developed despite intensive diuretic therapy. At this stage she was found to have developed heavy proteinuria and was referred to hospital. On admission she was grossly oedematous but not dyspnoeic. The jugular venous pressure was not raised. Initially only a pansystolic murmur was audible at the cardiac apex, though later an

- St. Thomas's Hospital and Medical School, London S.E.1. opening snap and mid-diastolic murmur characteristic of mitral stenosis appeared (see below).

Investigations on admission: Hb 15.6 g./100 ml., P.C.V. 50\%, E.S.R. $117 \mathrm{~mm}$. in one hour, blood urea $76 \mathrm{mg} . / 100 \mathrm{ml}$., plasma creatinine $1.3 \mathrm{mg} . / 100 \mathrm{ml} ., 24$-hour creatinine clearance $43 \mathrm{ml}$./ min., plasma cholesterol $860 \mathrm{mg} . / 100 \mathrm{ml}$., plasma albumin $3.0 \mathrm{~g} . /$ $100 \mathrm{ml}$., plasma protein electrophoresis showed increased alpha-2 globulin and gammaglobulin, urinary protein excretion 10-27 g./ 24 hours. High dose intravenous pyelogram was normal; chest $x$-ray picture showed an increase in the transverse diameter of the heart with evidence of increased pulmonary blood flow through the upper zones.

Percutaneous renal biopsy revealed glomeruli which appeared normal in the light microscope. In contrast, there was tubular atrophy with vacuolation of the epithelial cells of the proximal convoluted tubules. Focal collections of chronic inflammatory cells were present in interstitial tissues together with interstitial fibrosis. There was no evidence of disease of the arteries or veins. Electronmicroscopy revealed a widespread uniform basement membrane thickening of the glomerular tuft to $920 \mathrm{~m} \mu$, combined with a partial fusion of the epithelial cell foot processes (Special Plate, Fig. 1). Striking changes were seen in the tubules; the proximal convoluted tubules showed marked degenerative changes with extreme electron density of the cytoplasm and gross vacuolation (Special Plate, Fig. 2). The vacuoles were predominantly due to expansion of the intercellular space (Special Plate, Fig. 3), being limited by the cell junctions at the luminal surface. Some of the tubular cells had lost their microvilli, and these cells were being extruded into the lumen of the tubule, A minority of proximal convoluted tubules appeared well preserved, though the vacuolation of the cytoplasm was rather more pronounced than usual. In the distal convoluted tubules and in the collecting tubules individual cells appeared degenerate, and were separated from the surrounding cells.

In view of the "minimal" histological change in the glomeruli on light microscopy, the patient was treated with prednisone in an initial dose of $60 \mathrm{mg}$. daily. The rapid and complete remission of the nephrotic syndrome which followed can be seen from Fig. I. After three months of steroid treatment the drug was withdrawn, and eight weeks later neither proteinuria nor oedema had recurred, and the serum albumin remained normal.

\section{Case 2}

A man aged 64 presented in June 1967 with a nine-month history of angina of effort and ankle oedema which had been treated without success with a thiazide diuretic. He had never received organic mercurials. On examination the jugular venous pressure was not raised but there was marked ankle oedema. There was palpable left ventricular hypertrophy, and the murmurs of aortic 